\title{
Diving Injuries Presenting to the Hyperbaric Chamber in Barbados: A Review from 1995-2009
}

\author{
A Mansingh ${ }^{1}$, P Singh $^{1}$, W Palmer ${ }^{2}$, V Best ${ }^{3}$
}

\begin{abstract}
Objectives: This review sought to determine the epidemiology of diving injuries in Barbados and outcomes of treatment.

Methods: This retrospective study is a review of medical notes from January 1995 to December 2009, from the hyperbaric chamber at the Barbados Defense Force. Data included age at time of injury, gender, nationality, residence and diving a ccident. Injury-specific data included time from onset of injury to treatment, presenting signs and symptoms and dia gnosis. The number of treatments performed and their outcomes were also noted.

Results: During this period, 183 cases presented to the hyperbaric unit. Males accounted for $82 \%$ of the ca ses. The average age was 36.25 years (range: 17-79 yea rs). Half lived in the Caribbean and dived mainly for work. Sport diving was responsible for $51.4 \%$ of the cases presenting to the unit. Decompression sickness Type 2 comprised $56 \%$ of the ca ses. Neurological symptoms were common, with numbness, weakness and strange sensations affecting 45.4, 43.7 and $47.5 \%$, respectively. There was a mean of 3.35 treatments and $63.9 \%$ showed complete resolution of symptoms, and a further $25 \%$ showed improvement after treatment.

Conclusion: Diving is a relatively safe activity but decompression illness does occur at times. The number of cases presenting to the unit decreased over the 15-year period for various reasons. However, the unit continues to have very good outcomes for those treated.
\end{abstract}

Keywords: Barbados, decompression illness, diving injuries

\section{Lesiones de Buceo que se Presentan en la Cámara Hiperbárica en Barbados: Una Revisión de 1995 - 2009}

\author{
A Mansingh ${ }^{1}, \mathrm{P}_{\text {Singh }}{ }^{1}, \mathrm{~W}$ Palmer ${ }^{2}, \mathrm{~V}$ Best $^{3}$
}

\begin{abstract}
RESUMEN
Objetivos: Esta revisión tuvo por objeto determinar la epidemiología de las lesiones de buceo en Barbados y los resultados del tratamiento.

Métodos: Este estudio retrospectivo es una revisión de notas médicas desde enero de 1995 a diciembre de 2009, de la cámara hiperbárica de las Fuerza de Defensa de Barbados. Los datos incluyeron: edad en el momento de la lesión, género, nacionalidad, residencia, y accidentes de buceo. Los datos específicos de lesiones incluyeron el tiempo de ocurrencia de la lesión hasta el l tratamiento, los signos y síntomas presentados, y el diagnóstico. También se observaron el número de tratamientos realizados y sus resultados

Resultados: Durante este periodo, se presentaron 183 casos a la unidad hiperbárica. Los hombres representaron el 82\% de los casos. La edad promedio fue 36.25 años (rango: 17-79 años).
\end{abstract}

From: ${ }^{1}$ Division of Sports Medicine, The University of the West Indies, Kingston 7, Jamaica, West Indies, ${ }^{2}$ Maxwell Hill, Christchurch, Barbados and ${ }^{3}$ Department of Surgery, Radiology, Anaesthesia and Intensive Care, The University of the West Indies, Kingston 7, Jamaica, West Indies.
Correspondence: Dr A Mansingh, Division of Sports Medicine, The University of the West Indies, Kingston 7, Jamaica, West Indies. Email: akshai.mansingh@uwimona.edu.jm 
La mitad vivian en el Caribe y buceaban principalmente para el trabajo. El buceo deportivo representó el $51.4 \%$ de los casos que acudieron a la unidad. La enfermedad de descompresión tipo 2 comprendió el $56 \%$ de los casos. Los sintomas neurológicos fueron comunes, a los que se sumaban entumecimiento, debilidad y sensaciones extrañas que afectaron al 45.4, 43.7 y 47.5\%, respectivamente. Hubo una media de 3.35 tratamientos. El $63.9 \%$ mostró completa resolución de los síntomas y otro 25\% mostró mejoría después del tratamiento.

Conclusión: El buceo es una actividad relativamente segura, pero la enfermedad de descompresión ocurre a veces. El número de casos que se presentan a la unidad disminuyó por diversos motivos en un periodo de 15 años. La unidad continúa obteniendo muy buenos resultados con todos los que se someten a tratamiento.

Palabras claves: Barbados, enfermedad de descompresión, heridas de buceo

West Indian Med J 2017; 66 (2): 263

\section{INTRODUCTION}

Undersea diving is popularly performed in the Caribbean as a sport, mainly by tourists, professionally by military or police (dive and rescue) or commercially for fishing. The main methods are: (i) free diving (without breathing apparatus), (ii) snorkelling, and (iii) scuba (self-contained undersea breathing apparatus), or surface-supplied diving (1).

Though diving is generally safe, injuries to the neck, decompression sickness, oxygen toxicity, nitrogen narcosis, drowning, shallow water black-out and barotrauma may occur (1). There is even evidence showing long-term physical and psychological effects (2).

Decompression sickness (DCS) occurs with rapid ascent from a dive leading to bubble formation of dissolved gas in tissues and blood. This can either directly damage organs, or lead to arterial gas embolization (AGE) to the brain, causing loss of consciousness, paralysis or even death (3). It is a clinical diagnosis seen in less than $1 \%$ of divers $(4,5)$. There are two types: Type 1 DCS (DCS 1) characterized by mild pains which resolve within 10 minutes, pruritis and/or skin rash. Type 2 DCS (DCS 2) characterized by pulmonary symptoms, hypovolemic shock or neural involvement $(3,6)$. Suddenness of symptoms differentiates AGE from DCS 2, though both are treated similarly.

The main factors to consider in DCS are presence of neurological symptoms, onset time of symptoms, joint pain, relief after decompression therapy and maximum depth of the last dive. For AGE, main factors are onset of symptoms, altered consciousness, neurological symptoms, weakness and seizures (3). For patients with DCS, early stabilization and administration of $100 \%$ oxygen has been shown to improve outcome (7), especially those who cannot reach a hyperbaric facility quickly. Aspirin should also be given for its anti-platelet effect.

Persons with mild DCS 1 usually require administration of $100 \%$ oxygen at sea level only, but need close observation. Hyperbaric oxygen therapy is considered the definitive treatment for DCS 2. This re-pressurizes the bubbles to be re-dissolved into the tissues and blood. The patient is slowly taken back to surface atmospheric pressure allowing gases to gradually diffuse out of the lungs and body. The affected diver should be referred for hyperbaric oxygen, even if improving, as relapse is always a possibility.

The hyperbaric chamber at the Barbados Defense Force is the only one in Barbados and the neighbouring Islands. Previous studies looked at injuries seen at this facility between 1985 and $1994(8,9)$. This study looked at the injuries and outcomes that presented over the subsequent fifteen years.

\section{SUBJECTS AND METHODS}

A retrospective study of records of all divers treated at the hyperbaric chamber in Barbados between January 1995 and December 2009 was undertaken. All diving-related injuries that required hyperbaric treatment were included; those treated for non-diving injuries were excluded.

Data collected included age at injury, gender, nationality, place of residence and place of diving accident. Injury-specific data included the time from the onset of injury to treatment, clinical features at presentation, body area affected, number of treatments performed and outcomes (which was based on neurological examination at the end of decompression therapy). Other information that was documented included the number of divers that 
presented more than once, and significant complications that arose.

Statistical analysis was done using the SPSS software. Stata statistical software (version 10.1) was used for the non-parametric test for trend. Approval for the study was obtained from the Ethics Committee of the University Hospital of the West Indies/The University of the West Indies/Faculty of Medical Sciences, Mona, Jamaica and the Barbados Defense Force.

\section{RESULTS}

There were 183 cases presenting to the hyperbaric chamber between January 1995-December 2009, with 150 $(82 \%)$ males and 33 (18\%) females with ages ranged from 17 to 79 years [mean $36.25 \pm 9.95$ years] (Fig. 1). Most injuries (36.6\%) occurred in the 30-39-year age group, followed by the 20-29 (25.7\%) and 40-49 (25.1\%)-year age groups.

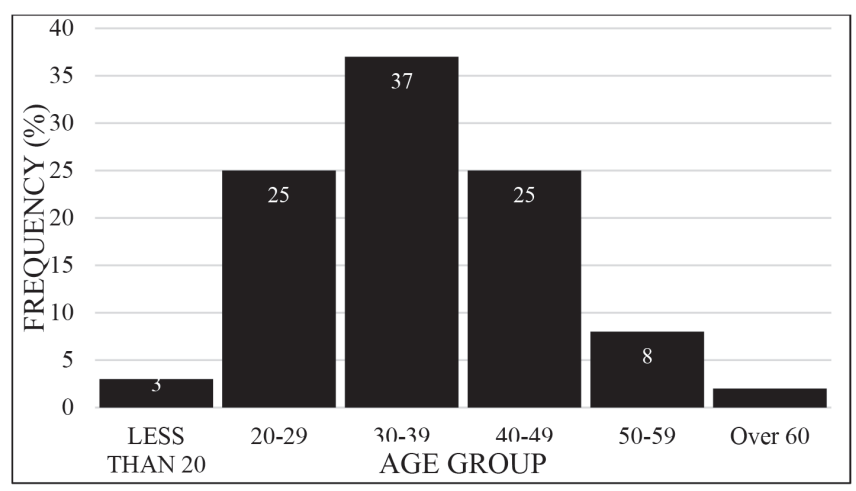

Fig. 1: Percentage of persons in various age groups presenting to the hyperbaric chamber at the Barbados Defense Force during January 1995-December 2009.

Patients treated came from 16 countries. Six were Caribbean countries accounting for $48 \%$ of the total (Table 1). Diving accidents took place in 12 islands, with the majority (56.8\%) occurring in Barbados (Table 1).

There was a steady decline in cases treated over the period with 33 and 25 cases treated in 1995 and 1996, respectively, compared to 1 and 2 cases in 2008 and 2009, respectively (Fig. 2).

Injuries were treated in every month with insignificant ( $p=0.440)$ differences between months (Fig. 3).

The majority (51.4\%) of injuries were from sports followed by fishing and lobster-catching (34.5\%) and work-related dives $(9.8 \%)$. The remainder did not have a reason recorded. First diving accidents comprised $69.9 \%$ of patients. The remainder had presented with at least one $(17.5 \%)$ to four $(0.5 \%)$ previous accidents, with $14.8 \%$ having presented previously to the local chamber.
Table 1: Frequency of the places of residence of cases and location where diving accident occurred

\begin{tabular}{lcc}
\hline & $\begin{array}{c}\text { Country of origin } \\
(\mathbf{\%})\end{array}$ & $\begin{array}{c}\text { Site of accident } \\
(\mathbf{\%})\end{array}$ \\
\hline Antigua & - & 0.5 \\
Australia & 0.5 & - \\
Barbados & 24.6 & 56.8 \\
Belgium & 0.5 & - \\
Bequia & - & 7.7 \\
Canada & 2.7 & - \\
Cariacou & - & 0.5 \\
Dominica & 0.5 & 0.5 \\
Germany & 2.2 & - \\
Grenada & 11.5 & 12.6 \\
Italy & 0.5 & - \\
Mustique & - & 3.3 \\
Norway & 0.5 & - \\
Puerto Rico & - & 1.6 \\
St Lucia & 5.5 & 8.2 \\
St Vincent & 12.0 & 5.5 \\
Sweden & 0.5 & - \\
Switzerland & 0.5 & - \\
Trinidad & 0.5 & - \\
Union Island & - & 2.2 \\
United Kingdom & 19.1 & - \\
United States of America & 18.0 & 0.5 \\
US Virgin Island & - & $\mathbf{1 0 0 . 0}(\mathbf{n}=\mathbf{1 8 3})$ \\
\hline Total & $\mathbf{1 0 0 . 0}(\mathbf{n}=\mathbf{1 8 3}$ & \\
& & - \\
& & \\
\hline
\end{tabular}

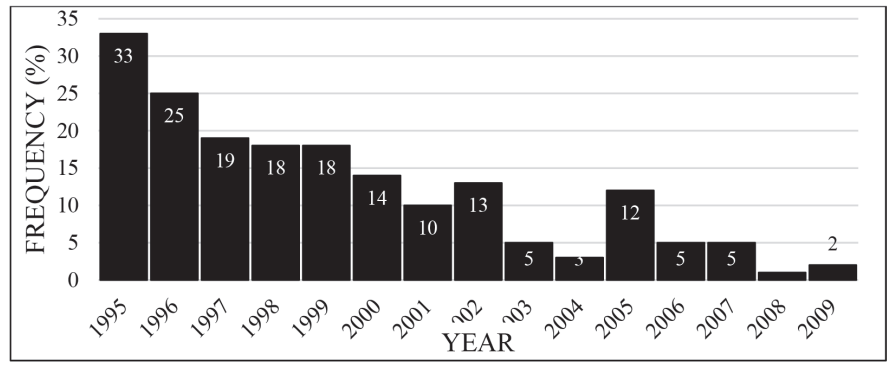

Fig. 2: Annual frequency of cases presented to the hyperbaric chamber at the Barbados Defense Force during January 1995-December 2009.

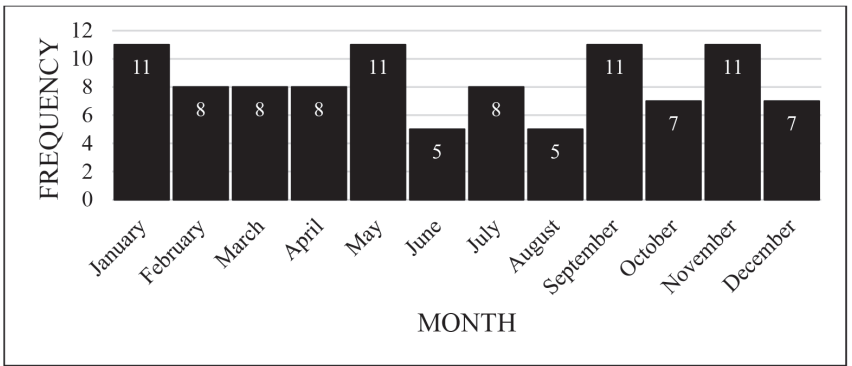

Fig. 3: Cases presenting per month to the hyperbaric chamber at the Barbados Defense Force during January 1995-December 2009. 
Table 2: Number of patients and time for presentation to the hyperbaric chamber

\begin{tabular}{lrrrrr}
\hline Site of Accident & \multicolumn{5}{c}{ Time from symptom onset to chamber arrival } \\
& $<$ 6 hours & $\mathbf{7 - 1 2}$ hours & $\mathbf{1 3 - 2 4}$ hours & $\mathbf{2}$ hours & Total \\
\hline St Vincent & 4 & 0 & 6 & 0 & 10 \\
Barbados & 42 & 11 & 28 & 12 & 93 \\
Mustique & 3 & 2 & 0 & 0 & 5 \\
Grenada & 3 & 8 & 4 & 7 & 22 \\
Puerto Rico & 0 & 0 & 3 & 0 & 3 \\
Bequia & 7 & 3 & 2 & 0 & 12 \\
US Virgin Island & 0 & 0 & 1 & 0 & 1 \\
Union Island & 1 & 1 & 0 & 2 & 4 \\
St Lucia & 0 & 1 & 8 & 5 & 14 \\
Antigua & 0 & 0 & 1 & 0 & 1 \\
Cariacou & 0 & 0 & 1 & 0 & 1 \\
\hline Total & $\mathbf{6 0}$ & $\mathbf{2 6}$ & $\mathbf{5 4}$ & $\mathbf{2 6}$ & $\mathbf{1 6 6}$ \\
\hline
\end{tabular}

Arrival time to the hyperbaric chamber was recorded in 166 cases, with a mean time of 18.7 hours and median 12 hours (Table 2).

The most commonly diagnosed condition was DCS two (59.6\%) followed by DCS 1 (29.0\%), AGE (6.4\%) and $5 \%$ were unclear. The chief presenting complaint was pain, mainly in the limbs. Neurological symptoms included weakness, numbness and imbalance (Table 3). Pain was predominantly seen in DCS two patients $(64.6 \%)$.

Table 3: Frequency of presenting symptoms

\begin{tabular}{lcc}
\hline Symptom & Frequency & Per cent \\
\hline Pain-head & 31 & 16.9 \\
Pain-back & 40 & 21.9 \\
Pain-neck & 24 & 13.1 \\
Pain-chest & 22 & 12 \\
Pain-abdomen & 35 & 19.1 \\
Pain-limbs & 89 & 48.6 \\
Pain-shoulders & 51 & 27.9 \\
Pain-hips & 31 & 16.9 \\
Unconsciousness & 11 & 6 \\
Shock & 4 & 2.2 \\
Vertigo & 46 & 25.1 \\
Visual difficulty & 12 & 6.6 \\
Nausea/vomiting & 44 & 26 \\
Difficulty hearing & 14 & 7.7 \\
Speech difficulty & 5 & 2.7 \\
Imbalance & 59 & 32.2 \\
Numbness & 83 & 45.4 \\
Weakness & 80 & 43.7 \\
Strange sensations & 87 & 47.5 \\
Air under skin & 4 & 2.2 \\
Skin changes & 5 & 2.7 \\
Unknown & 14 & 7.7 \\
\hline & &
\end{tabular}

Most patients $(84.7 \%)$ required five or less treatments $(50.8 \%$ required only one) with a mean of 3.4 treatments. However, the length of each treatment was not recorded. Complete recovery was noted in $63.9 \%$ of patients, with improvement in another $22.4 \%$ (Table 4 ). The majority $(35.9 \%)$ of patients who showed complete recovery were $30-39$ years old. There was no change in $3.3 \%$ of patients and $1.6 \%$ (all males) died. There was no statistical difference in the clinical outcomes among the various age groups.

Of the three deaths, only one of these patients took more than 24 hours to reach the unit for treatment. The other two received treatment in less than five-hours of the onset of the symptoms.

\section{DISCUSSION}

The 183 cases treated over the 15 -year period at the hyperbaric chamber at the Barbados Defense Force, ranged from a high of 33 cases per year to a low of two cases. In European hyperbaric units annual averages ranged from 10 to 100 cases (10). There are more persons diving worldwide, resulting in more diving accidents (11). However, in Barbados, the mean number of accidents decreased annually from 15 cases during 1985-1995 to 12.2 cases during 1995-2009 (9). This may be attributed to better education of divers, and the presence of more hyperbaric chambers in the Caribbean. All patients may not be presenting, especially uninsured individuals, such as some fishermen from neighbouring islands.

Males predominated (82\%), similar to the previous 10 years [87.3\%] (9) and to other studies: $76 \%$ presenting to the Red Sea Medical Centre, and $84 \%$ in the United Kingdom (UK) study $(12,13)$. The average age 
(36.25 years) of patients in this study was similar to the average age (34 years) of persons treated between 1985 and 1995 (9), and was comparable to studies from Poland [34.6 years] (10) and the UK [30-39 years] (13). The DAN 2008 report revealed that male divers' age peaked at 40-49 years old, while female divers' age was constant in the 30-59-year age range (11).

Significant increases in risk of serious injury and incomplete recovery has been reported above the age of 50 years (14). This was not seen in this study, where the majority of persons over 50 years either improved or completely recovered.

Barbadian patients were seen most, followed by those from the UK and United States of America (USA), reflecting the popularity of the Caribbean for tourists. There were many cases from St Vincent and the Grenadines which is near to Barbados.

Sport diving injuries accounted for most (51.4\%) persons presenting during 1995-2009, up from the 44.7\% in the 1985-1995 period (9). This was in contrast to a military hospital-based hyperbaric chamber in Malaysia during 1996-2004, where commercial diving activity accounted for $48 \%$ of the cases, followed by recreational (39.2\%) diving (15), and not as much as in the UK, where $81 \%$ of the divers were recreational and only $10 \%$ were occupational divers (13).

Outcomes are significantly affected by the initial treatment and the time it takes to get definitive treatment $(13,16)$. The time taken to commence treatment from the onset of symptoms was similar to that in Poland, where the median time interval from first symptom occurrence to start of recompression was 32.5 hours [range was $2-193.5 \mathrm{hrs}$ ] (10). The average-time to treatment in this study was 18.67 hours, with one-third of the patients arriving in less than six hours. Delays may occur due to many factors, starting with delay in presentation to the primary healthcare provider, delay in diagnosis, and delay in the necessary air transport when needed. Such delays would be expected as several Islands refer patients to the unit for treatment.

The neurological symptoms seen in DCS two were similar to those in the UK, which had $77 \%$ of cases with neurological symptoms $(13,17)$. It is recognized that many patients requiring hyperbaric treatment have one or more neurological symptoms (18). The most common neurological symptoms were numbness, weakness and strange sensations. In the USA, numbness was the predominant presenting complaint in DCS (59\% of cases), while sensory abnormalities (76.6\%) and motor weakness $(35.1 \%)$ were common in the UK $(13,19)$. Sensory disturbance was seen in $67.5 \%$ of the cases in Cozumel, Mexico and altered consciousness in 10\% $(17,19)$.

It appears that there were fewer persons who experienced specific neurological symptoms in this study than reported in other studies, although it should be noted that many of the studies combined the various symptoms. Differences in reporting or documentation may account for the disparity in cases. However, if all documentation is assumed equal, the lower percentages seen in our study may be a reflection of less severe diving-related complications. Diving in the Caribbean is associated with warmer, clearer waters and the absence of major cave diving. Less dangerous diving may result in less serious injuries.

Pain is felt in $55-62 \%$ of decompression illness cases overall $(13,16), 70-85 \%$ in DCS 1 but only $30 \%$ in DCS two cases (3). Shoulder pain in particular has been described in $25 \%$ of cases $(6,20)$. In this study, the majority of cases with pain, (except shoulder pain) had DCS two. In Mexico, 54.5\% of the 200 persons treated for DCS experienced arthralgia or myalgia (18), similar to this study.

Headaches have been described in $25 \%$ of cases but were seen in only $16.9 \%$ of cases in this study. The usual causes are sinusitis, migraines, cold exposure and tight face mask. However, recognition and early treatment of more serious conditions such as intracerebral bubbles need to be treated as emergencies.

In this study, $56.6 \%$ of cases requiring hyperbaric treatment were DCS two, and $29 \%$ DCS one. A few cases with possible barotrauma, and inconclusive diagnosis constituted $5.5 \%$ of cases labelled "Other". It is recognized that re-pressurisation in a hyperbaric chamber should be performed if the diagnosis is not clear as this form of treatment would be considered both diagnostic and therapeutic. These findings compare to other recent studies. Over $42 \%(n=453)$ of patients had DCS two and $26 \%$ had DCS one at the Hyperbaric Chamber of the Red Sea Medical Unit, and only 13\% of the cases in the UK had DCS one (13). However, the Polish five-year study showed that $76.5 \%$ of cases were DCS one (10). Diving injuries may have negative long-term effects, particularly after decompression illness (2), and it is important that follow-up be performed. It is recommended that treatment continues until the patient reaches a clinical plateau (21). In this study, some premature discontinuation took place at the patient's request, or for financial reasons.

The majority $(84.7 \%)$ of patients required less than five treatments (mean 3.35), which was comparable to 
other studies (10). The duration of each session, however, was not recorded in this study which would have been useful as well.

The majority of cases had complete resolution $(63.9 \%)$ or partial improvement $(22.4 \%)$ of symptoms after receiving hyperbaric treatment, similar to other published data reporting complete recovery in $48-70 \%$ of cases and partial recovery in $27-30 \%$ of cases $(10,21$, 22). Long-term residual symptoms were seen in $24.5 \%$ (10). Severe cases were treated most rapidly at a facility in Aberdeen and still had poor outcomes (23), suggesting that rapid treatment does not always mean an excellent outcome. However, details of the cases were not available to draw further conclusions.

Better outcome rates were seen in more recent studies, suggesting improvement in care, including use of oxygen as part of the initial first aid management. The UK experience showed a drop in residual symptoms from approximately $25 \%$ to $18 \%$ between two studies (13).

Scuba diving deaths are rare and in this study, there were three deaths. However, these were patients presenting to the facility, and deaths prior to presentation are unknown. Over the past three decades, big diving communities such as Canada and the USA combined to have 70 deaths or more per year whereas smaller communities like the UK and Australia had 10 or less fatalities per year (11). The average age of those persons that died in this study was 32.7 years, a decade younger than male divers insured by DAN. The Caribbean deaths were in either fishing or lobster diving, which only accounted for $20 \%$ of deaths in USA and Canada.

There was very little literature on repeat presentations of DCS in the same individual. In this study $17.5 \%$ of cases presented for the second time and 5.4\% with two or more previous accidents. This brings into question how much education is given to divers after they have had a diving injury.

Limitations of this study include the assumption that protocols and definitions for the diagnosis of all types of DCS were standard. Only those cases presenting to the hyperbaric chamber were studied, so the true incidence of diving injuries is not known. A lot of the information was based on memory recall of the patients, especially regarding previous presentations.

Although it is recognized that diving is a relatively safe sport, accidents do occur and may result in debilitating outcome. The BDF Hyperbaric Unit continues to have very good outcomes in the treatment of decom- pression illness. It is recommended that there be ongoing education for healthcare providers, divers and dive shop operators. This would assist in the early recognition of decompression illness.

\section{ACKNOWLEDGEMENTS}

The authors wish to acknowledge Dr Kathy Dalip for her assistance with this paper.

\section{REFERENCES}

1. Underwater diving. [rev 14 Sept 2014; cited 5 Nov 2014]. Available from: http://en.wikipedia.org/wiki/Underwater_diving.

2. McQueen D, Kent G, Murrison A. Self-reported long term effects of diving and decompression illness in recreational scuba divers. Br J Sports Med 1994; 28: 101-4.

3. Freiberger JJ, Lyman SJ, Denble PJ, Pieper CF, Vann RD. Consensus factors used by Experts in the Diagnosis of Decompression Illness. Aviat Space Environ Med 2004; 75: 1023-8.

4. Vann RD. Report on decompression illness, diving fatalities and project dive exploration; DAN's annual review of recreational scuba diving injuries and deaths based on 2000 data. Diver's Alert Network 2002: 88.

5. Bennett PB. What me bent? Divers Alert Network 1997; 2.

6. Pulley SA. Decompression sickness [Updated 17 Sept 2009; cited Nov 5, 2014]. Available from http://emedicine.medscape. com/article/769717-overview

7. Longphire JM, Denoble PJ, Moon RE, Vann RD, Freiberger JJ. First aid normobaric oxygen for the treatment of recreational diving injuries. Undersea Hyperb Med 2007; 34: 43-9.

8. Roach TC, Gittens FE. Initial experience with recompression chamber therapy in Barbados. West Indian Med J 1987; 36 (Suppl): 34.

9. Gittens FE, Roach TC, Binks D. SCUBA diving accidents in the Caribbean. West Indian Med J 1994; 43 (Suppl 1): 36.

10. Kot J, Sicko Z, Michalkiewicz M, Lizak E, Góralczyk P. Recompression treatment for decompression illness: 5-year report (2003-2007) from National Centre for Hyperbaric Medicine in Poland. Int Marit Health 2008; 59: 69-80.

11. Pollack N Ed. Annual Diving Report - 2008 Edition, Durham, NC: Divers Alert Network, 2008

12. Dankner R, Gall N, Freidman G, Arad J. Recompression treatment of red sea diving Accidents: 23 year Summary. Clin J Sports Med 2005; 15: 253-6.

13. Francis J. Decompression Illness in sports divers The UK experience. SPUMS Journal 1998; 28:

14. Smerz RW. Age associated risks of recreational scuba diving. Hawaii Medical Journal 2006; 65: 140-2.

15. Rozali A, Khairuddin H, Sherina MS, Halim MA, Zin BM, Sulaima A. Diving accidents treated at a military hospital based recompression chamber facility in Peninsular Malaysia. Med J Malaysia 2008; 63: 91-5.

16. Ball R. Effect of severity, time to recompression with oxygen, and re treatment on outcome in forty nine cases of spinal cord decompression sickness. Undersea and Hyperbaric Med 1993; 20 : 133-45.

17. Hart AJ, White SA, Conboy PJ, Bodiwala G, Quinton P. Open water Scuba diving accidents at Leicester: five years' experience. J Accid Emerg Med 1999; 16: 198-200. 
18. Newton HB, Padilla W, Burkart J, Pearl DK. Neurological manifestations of decompression illness in recreational divers - the Cozumel experience. Undersea Hyperb Med 2007; 34: 349-57.

19. Torrey SA, Webb SC, Zwingelberg KK. Comparative Analysis of Decompression Sickness: Type and Time of Onset. J Hyperbaric Med 1987; 2: 2 .

20. Kindwall EP, Whelan HT. Management of Complications in Hyperbaric Treatment Hyperbaric Medicine Practice $3^{\text {rd }}$ Edition Best Publishing Co p 291
21. Barratt DM, Harch PG, Meter KV. Decompression Illness in Divers: A review of the literature. The Neurologist 2002; 8: 186202.

22. Gil A, Shupak A, Lavon H, Adir Y. Decompression sickness in divers treated at the Israel Naval Medical Institute between the years 1992 to 1997. Harefuah 2000; 138: 751-4.

23. Ross JAS, Stephenson RN, Godden DJ, Watt SJ. The presentation and clinical course of decompression illness in Scotland. UHMS Meeting Abstract 2000. 